\title{
Exercise-Induced Bronchoconstriction in College Athletes: Are We Doing Enough?
}

More Americans than ever before have asthma, and although the disease can be managed with proper trigger prevention and treatment, there are still a significant number of deaths. The Centers for Disease Control and Prevention report that 1 in 14 people have asthma, with 3,651 deaths reported in 2014 at an annual cost of $\$ 56$ billion., ${ }^{1,2}$ Adults are nearly 7 times more likely to die from asthma than children. ${ }^{3}$ A comprehensive review of 195 asthma deaths in the United Kingdom during 2012-2013 found that almost half died without emergency medical response or any medical assistance, and the majority were not being cared for by a medical specialist during the year before their deaths. Only one quarter had asthma action plans or acknowledged concern for their disease, and there was evidence of excessive use of short-acting beta agonists, under-prescribing of preventive medication, and possibly inappropriate prescribing of long-acting $\beta$-agonist bronchodilator inhalers as monotherapy. The authors concluded that improved access to appropriate asthma medication should be a goal to reduce asthma mortality worldwide. ${ }^{4}$

D'Alonzo and colleagues recognize that a deadly episode of asthma can occur that is unrelated to the severity or stability of the disease. These researchers tracked asthma deaths in athletes and found $>100$ deaths related to asthma in a 2-y period. This group believes that proper treatment and prophylaxis improves health and performance and may reduce the risk of fatal asthma exacerbations. ${ }^{5,6}$ There are, unfortunately, several high-profile examples of mortality in athletes secondary to asthma. For example, a 21-y-old potential major league baseball player from Sarasota, Florida, arrived in Mesa, Arizona for intensive coaching. He was aware that he had exercise-induced bronchoconstriction (EIB) and used an inhaler. He died shortly after a training session from possible complications of asthma.

In 2001, a Northwestern University football player, age 22 , collapsed during football practice and died an hour later.

\footnotetext{
Ms DeJuilio has disclosed no conflicts of interest.

Correspondence: Patricia DeJuilio MSc RRT-ACCS RRT-NPS, Clinical Director, Respiratory Care and Sleep Medicine, Northwestern Medicine/ Central DuPage Hospital, 25 North Winfield Road, Winfield, IL 60190. E-mail: patricia.dejuilio@cadencehealth.org.
}

DOI: $10.4187 /$ respcare. 04982
His teammates witnessed him having asthma exacerbations many times and thought this time was no different. ${ }^{7}$

\section{See the Original Study on Page 897}

A 13-y-old young man collapsed and died during football practice from an asthma exacerbation as revealed by autopsy. He had never been diagnosed with asthma and therefore did not have a plan or prophylaxis to treat his disease. ${ }^{8}$

In this issue of RESPIRATORY CARE, Burnett et a ${ }^{9}$ found that $29 \%$ of college athletes report a past history of EIB or asthma; however, many athletes who experience symptoms of EIB may not have medical care or a formal diagnosis. These findings are consistent with previous studies. ${ }^{5,6}$ Almost half of these athletes reported experiencing symptoms. This is very concerning because it suggests that there are many young athletes with EIB who have never been diagnosed and are, therefore, not treated and may be at risk for exacerbations and possibly death. Additionally, these athletes have not received education regarding signs and symptoms of EIB and may be unaware of the gravity of their symptoms. Most surveys rely on self-reporting symptoms and disease diagnosis, which makes it possible that there are many undiagnosed and untreated people with EIB who are not included in current data, including Burnett et al. ${ }^{9}$

The current evidence strongly supports the need for education and awareness regarding asthma for the public so that symptoms are recognizable, and for health-care providers so that appropriate treatment plans and symptom management can be prescribed. Gym teachers, athletic trainers, coaches, and peers may be the only witnesses to exercise-induced asthma events, which supports the need for education in all areas of a school and/or recreational system. Burnett et $\mathrm{al}^{9}$ state that the National Athletic Trainers Association guidelines suggest that trainers should understand the use and misuse of bronchodilators, although it is uncertain as to whether this guideline is followed or whether signs and symptoms are recognized by this group. Burnett et $\mathrm{al}^{9}$ found that many athletes who had a history of asthma took no medications to treat their condition. Although it is unknown whether sports performance will improve if asthma is treated appropriately in affected athletes, it is most likely that mortality could be reduced. Screening of all children and young adults as part of a mandatory physical for a sport may be appropriate to re- 
duce asthma-related deaths. All patients with history of asthma or those with special circumstances should be screened utilizing spirometry evaluations or exercise challenge testing or both. ${ }^{5}$

In summary, it is very possible that deaths continue to occur from EIB that could be avoided with proper treatment, action plans, and prophylaxis. Additionally, signs and symptoms of EIB should be taken very seriously, and Burnett et $\mathrm{al}^{9}$ and others have shown that this is not always the case. This team received support from a sports medicine group and coaches. However, this support (which should consist of education on the signs and symptoms of EIB, triggers, treatment, and prophylaxis) may not be available or provided at other institutions or organizations. This study supports the need for future educational programs that should include athletes, families, trainers, coaches, and teachers. The evidence to implement robust education programs and disease awareness exists. Studies to determine whether EIB-related deaths decrease when a consistently provided EIB screening is completed and appropriate treatments are in place and adhered to are needed.

Patricia DeJuilio MSc RRT-ACCS RRT-NPS Respiratory Care and Sleep Medicine Northwestern Medicine Central DuPage Hospital Winfield, Illinois

\section{REFERENCES}

1. Asthma and Allergy Foundation of America. Asthma facts and figures. August 2015. http://www.aafa.org/page/asthma-facts.aspx Accessed on April 22, 2016.

2. Centers for Disease Control and Prevention. Asthma. http://www. cdc.gov/asthma/default.htm. Accessed on April 22, 2016.

3. Centers for Disease Control and Prevention. Asthma facts: CDC's National Asthma Control Program Grantees. July 2013. http://www. cdc.gov/asthma/pdfs/asthma_facts_program_grantees.pdf. Accessed on April 22, 2016.

4. Strachan D, Limb E, Pearce N, Marks G. The global asthma report 2014: asthma mortality. http://www.globalasthmareport.org/burden/ mortality.php. Accessed on April 22, 2016.

5. Scott F. Athlete's death puts asthma in spotlight. Advance Respir Care Sleep Med Oct 1997. http://respiratory-care-sleep-medicine. advanceweb.com/Article/Athletes-Death-Puts-Asthma-inSpotlight.aspx. Accessed on April 22, 2016.

6. D’Alonzo G., Miller M, Weiler J. National Athletic Trainers' Association Position Statement: Management of Asthma in Athletes. J Athl Train 2005;40(3):224-245.

7. WebMD Health News. Tragic death sheds light on asthma dangers. 2001. http://www.webmd.com/asthma/news/20010813/tragic-deathsheds-light-on-asthmas-dangers. Accessed on April 22, 2016.

8. Kallstrom TJ. Asthma and the athlete. Allergy Asthma Health Sept 2008. http://www.yourlunghealth.org/healthy_living/aah/09.08/ articles/athlete/. Accessed on April 22, 2016.

9. Burnett DM, Vardiman JP, Deckert JA, Ward JL, Sharpe MR. Perception of exercise-induced bronchoconstriction in college athletes. Respir Care 2016;61(7):897-901. 